\title{
Opioid use in Texas in 2016
}

\begin{abstract}
Jane Carlisle Maxwell, $\mathrm{PhD}$, in the Addiction Research Institute in the School of Social Work at the University of Texas issued a report on substance abuse trends in Texas in 2016 on November 6, 2017. In 2016 Poison Control Centers received 1,234 calls regarding opioid abuse and misuse. The most frequent calls concerned heroin. In 2016 there were 15,106 admissions for opioid treatment; heroin accounted for 10,822 admissions. The average age of these admissions was 34 years. The routes of drug administration included injection (83\%) and inhalation (14\%). In 2016, 1440 deaths in Texas included a notation of substance abuse with opioids. Again, heroin had the largest number of deaths (539) associated with substance abuse in the opioid category. The average age of those who died was 37 years. In 2016 forensic toxicology laboratories reported 8,075 positive laboratory test for opioids. The most frequent opioid identified was heroin with 5,274 positive tests.
\end{abstract}

In 2016 prescriptions for 11,474 doses of hydrocodone per 100,000 population in Texas were written. Most of the heroin in Texas comes from Mexico; products include Mexican black tar, powdered brown, and Mexican white heroin. Heroin costs 15-20 dollars per $100 \mathrm{mg}$. See the analysis by Berdine on the black market in opioids in this issue of the Southwest Respiratory and Critical Care Chronicles.

\section{K Nugent -3-30-2018}

Maxwell JC. Substance abuse trends in Texas 2017- A report to the national drug early warning system (Revised 11/6/2017). https://socialwork.utexas. edu/dl/ari/texas-drug-trends-2017.pdf.

This work is licensed under a Creative Commons Attribution-ShareAlike 4.0 International License. 